\title{
Erythrocyte sodium-lithium countertransport activity is related to membrane fluidity in IDDM patients
}

\author{
A. Dowd ${ }^{1}$, T.H. Thomas ${ }^{1}$, R. Taylor ${ }^{2}$, R. Wilkinson ${ }^{1}$ \\ ${ }^{1}$ Departments of Nephrology and Medicine, Freeman Hospital and University of Newcastle upon Tyne, Newcastle upon Tyne, UK \\ ${ }^{2}$ Department of Medicine, Royal Victoria Hospital and University of Newcastle upon Tyne, Newcastle upon Tyne, UK
}

\begin{abstract}
Summary Sodium-lithium countertransport (SLC) activity at a standard physiological sodium concentration is raised in uncomplicated IDDM, for which the kinetic mechanism is a raised maximum velocity $\left(\mathrm{V}_{\max }\right)$. Diabetic patients with nephropathy do not have raised values for $\mathrm{V}_{\max }$ but a low Michaelis constant $\left(\mathrm{k}_{\mathrm{m}}\right)$. Transporter activity could be influenced by its membrane lipid environment. This was assessed in 21 control subjects, 32 uncomplicated diabetic patients, 17 patients with diabetic nephropathy and 11 patients with nondiabetic nephropathy by measuring the fluorescence anisotropy of DPH and TMA-DPH to assess different membrane regions. Standard SLC was higher in all the patient groups compared to the control subjects: $0.307 \pm 0.020 \mathrm{mmol} \mathrm{Li} / \mathrm{h} \times 1$ cells in uncomplicated IDDM; $0.300 \pm 0.032$ in diabetic nephropathy patients and $0.276 \pm 0.019$ in non-diabetic nephropathy patients vs $0.216 \pm 0.011 \mathrm{mmol} \mathrm{Li} / \mathrm{h} \times 1$ cells in control subjects ( $p<0.001, p<0.05, p<0.05$, respectively). This was due to raised $V_{\max }$ values in the uncomplicated group: $0.528 \pm 0.035$ vs $0.385 \pm 0.022 \mathrm{mmol} \mathrm{Li} / \mathrm{h} \times 1$ cells in control subjects $(p=0.001)$ and low values for $\mathrm{k}_{\mathrm{m}}$ in the diabetic nephropathy group: 58 (27-170) vs 106 (81-
\end{abstract}

161) $\mathrm{mmol} / 1$ in control subjects $(p<0.001)$. Raised SLC in the non-diabetic nephropathy group was largely due to raised $V_{\text {max }}: 0.460 \pm 0.030 \mathrm{mmol} \mathrm{Li} / \mathrm{h} \times 1$ cells; $p=0.053$, with no difference in $\mathrm{k}_{\mathrm{m}}: 99.5(74-137)$. DPH anisotropy was lower in the uncomplicated diabetic patients $(0.210 \pm 0.0009)$ compared to the control subjects $(0.214 \pm 0.0007: p=0.006)$ and was related to both standard SLC $(r s=-0.68, p<0.001)$ and $\mathrm{V}_{\max }(r s=$ $-0.77, p<0.001)$. Though DPH anisotropy in the diabetic nephropathy group was not different from normal control subjects, it also correlated with SLC ( $r s=-0.72, p<0.001$ ) due to the same relationship with $\mathrm{V}_{\max }(r s=-0.73, p<0.001)$ as in uncomplicated diabetes. TMA-DPH anisotropy showed no difference between the four groups and was not related to either standard SLC, $\mathrm{V}_{\max }$ or $\mathrm{k}_{\mathrm{m}}$. Therefore, changes in membrane fluidity in the hydrophobic regions of the erythrocyte membrane may be responsible for some of the differences in SLC in IDDM. [Diabetologia (1994) 37 : 394-400]

Key words Sodium, lithium, erythrocyte, membrane fluidity, fluorescence polarization, DPH
Received: 29 June 1993

and in revised form 4 November 1993

Corresponding author: Dr. A. Dowd, Department of Nephrology, Freeman Hospital, Freeman Road, Newcastle upon Tyne NE7 7DN, UK

Abbreviations: SLC, sodium-lithium countertransport; DPH, 1,6-diphenyl-1,3,5-hexatriene; TMA-DPH, 1,4-trimethylammonium-3,5-hexatriene; IDDM, insulin-dependent diabetes mellitus; NIDDM., non-insulin-dependent diabetes mellitus.
Several studies have shown increased sodium-lithium countertransport activity (SLC) in IDDM [1-4]. Membrane fluidity has also been studied in diabetes but patient groups have varied and the results have been inconsistent [5-13]. The sodium-lithium countertransporter is a transmembrane protein with increased activity in some diabetic patients but its character has not been studied in relation to membrane fluidity in diabetes.

In IDDM, a raised SLC has been suggested as a possible marker for those patients at risk of nephropathy $[14,15]$. Measured under standard conditions of 
$150 \mathrm{mmol} / \mathrm{l}$ external sodium concentration, SLC could be raised due to either a low Michaelis constant with respect to external sodium (low $\mathrm{k}_{\mathrm{m}}$ ) or a raised maximum velocity $\left(\mathrm{V}_{\max }\right)$. In uncomplicated IDDM there appears to be an increase in the $V_{\max }$ of the transporter [4], whereas patients with diabetic nephropathy do not have raised values for $V_{\max }$ but have low values for $\mathrm{k}_{\mathrm{m}}$ [16].

The sodium-lithium countertransporter has no known physiological role and no satisfactory explanation has been proposed as to how a raised activity could directly influence the development of nephropathy in diabetes. A raised activity may be a marker of a more fundamental membrane abnormality. It has been shown that membrane lipids can regulate certain membrane proteins (such as transporters and receptors) either through specific interactions or as a result of more generalised properties of the membrane lipids such as their fluidity [17-21]. An altered fluidity could increase the rate of transporter turnover and therefore ion transport, with a resulting increase in $V_{\text {max }}$. Lipid properties around the transporter could affect ion binding and result in a change in $\mathrm{k}_{\mathrm{m}}$, although changes in ion translocation steps could also affect $k_{m}$.

Membrane fluidity can be assessed using fluorescent dyes which localise to particular regions of the membrane $[22,23]$. DPH is very hydrophobic and positions itself in the deep hydrophobic regions of the membrane lipids. TMA-DPH is more hydrophilic and localises to the more superficial, less hydrophobic regions of the membrane. The fluidity of the regions in which the dyes are situated affects their rate of rotation and hence the degree of depolarisation of fluorescent light. The anisotropy value is a quantitative expression for this effect.

Therefore the relationship of SLC activity to membrane fluidity, assessed from anisotropy measurements of DPH and TMA-DPH in erythrocyte membranes, was determined in IDDM patients with and without diabetic nephropathy, non-diabetic patients with nephropathy and a group of healthy control subjects.

\section{Subjects and methods}

\section{Patients}

Thirty-two uncomplicated patients with IDDM (initial presentation with weight loss and ketosis, and aged less than 30 years) were studied. These patients had diabetes of relatively short duration (less than the median for the onset of nephropathy). As previous studies have shown that SLC is not raised in uncomplicated IDDM of long duration [16,24], it is necessary to investigate membrane fluidity in relation to raised SLC in diabetic patients of relatively short duration. Criteria for patient selection to uncomplicated diabetes were: (i) no retinopathy on retinal photography; (ii) urine albumin excretion (measured by radioimmunoassay) of less than $15 \mu \mathrm{g} / \mathrm{min}$ in timed overnight collections; (iii) no impairment of glycaemic awareness; (iv) no symptomatic neuropathy. Patients with other factors known to affect SLC were excluded and no regular medication other than subcutaneous insulin was being taken. A group of 21 healthy control subjects, matched for age, sex and body mass index was studied for comparison. None was taking any regular medication or had a family history of essential hypertension.

A group of 17 patients with diabetic nephropathy was also studied. The diagnosis of diabetic nephropathy was made on the basis of established criteria, i. e. duration of diabetes of at least 10 years, persistent proteinuria as the first clinical feature, concomitant retinopathy (by retinal camera), no evidence of other renal or urinary tract disease and absence of cardiac failure. Renal biopsies had been performed in two patients and showed only common features of diabetic nephropathy. Of these 17 patients, 2 had end-stage renal failure and were on continuous ambulatory peritoneal dialysis, 10 had renal impairment with serum creatinine raised above $120 \mu \mathrm{mol} / 1$, and 5 had persistent proteinuria (Albustix positive on repeated occasions for at least 2 years and urinary protein excretion of more than $500 \mathrm{mg} / 24 \mathrm{~h}$, but serum creatinine less than $120 \mu \mathrm{mol} / \mathrm{l}$ ). In addition to insulin, 10 patients were also receiving anti-hypertensive medication: 6 patients on angiotensin converting enzyme inhibitors, 5 on calcium antagonists, 4 on diuretics and 2 on prazosin. Some patients were taking more than one anti-hypertensive drug.

A group of 11 non-diabetic patients with nephropathy (chronic pyelonephritis, adult polycystic kidney disease, obstructive uropathy, chronic glomerulonephritis or single kidney) was studied for comparison with the diabetic nephropathy group. Of these 11 patients, 2 had end-stage renal failure and were on continuous ambulatory peritoneal dialysis and 9 had serum creatinine above $120 \mathrm{mmol} / \mathrm{l}$. The patients were matched with the diabetic patients with nephropathy on the basis of age/sex distribution, body mass index and degree of renal impairment. Of these 11 patients, 3 were not receiving any antihypertensive medication, 4 were on calcium antagonists, 2 on diuretics, 2 on beta-blockers and 1 was on an angiotensin converting enzyme inhibitor.

Ethical approval for this study was granted by the Newcastle Health Authority/Newcastle University Joint Ethical Committee, and all subjects gave their informed consent.

\section{Evaluation of patients and subjects}

Details of patients and subjects are given in Table 1. Blood pressure (Korotkoff phases 1 and 5) was measured in the sitting position on at least three separate occasions and is presented as the mean arterial pressure (diastolic pressure plus one-third of the pulse pressure). The mean of the last three glycated haemoglobin concentrations (Ciba-Corning electroendosmosis, Halstead, UK: reference range $5.0-7.5 \%$ ) was used to assess glycaemic control. The plasma cholesterol and triglyceride concentrations were determined by enzymatic techniques using a centrifugal analyser with a kit supplied by Boehringer Mannheim (Mannheim, Germany). The samples were also examined for chylomicrons and if present, suggesting a non-fasting state, the data were discarded.

\section{Assay for the determination of standard SLC activity and its kinetic characteristics}

The details of the assay used to measure standard SLC activity, $\mathrm{k}_{\mathrm{m}}$ and $\mathrm{V}_{\max }$ are fully described in our previous reports $[4,16,25]$. Briefly, SLC activity was measured as sodium-stimulated lithium efflux from washed, lithium loaded erythrocytes (internal lithium concentration $>7.0 \mathrm{mmol} / \mathrm{l}$ ). Erythrocytes were incu- 
Table 1. Clinical details of control subjects, diabetic patients and nephropathy patients

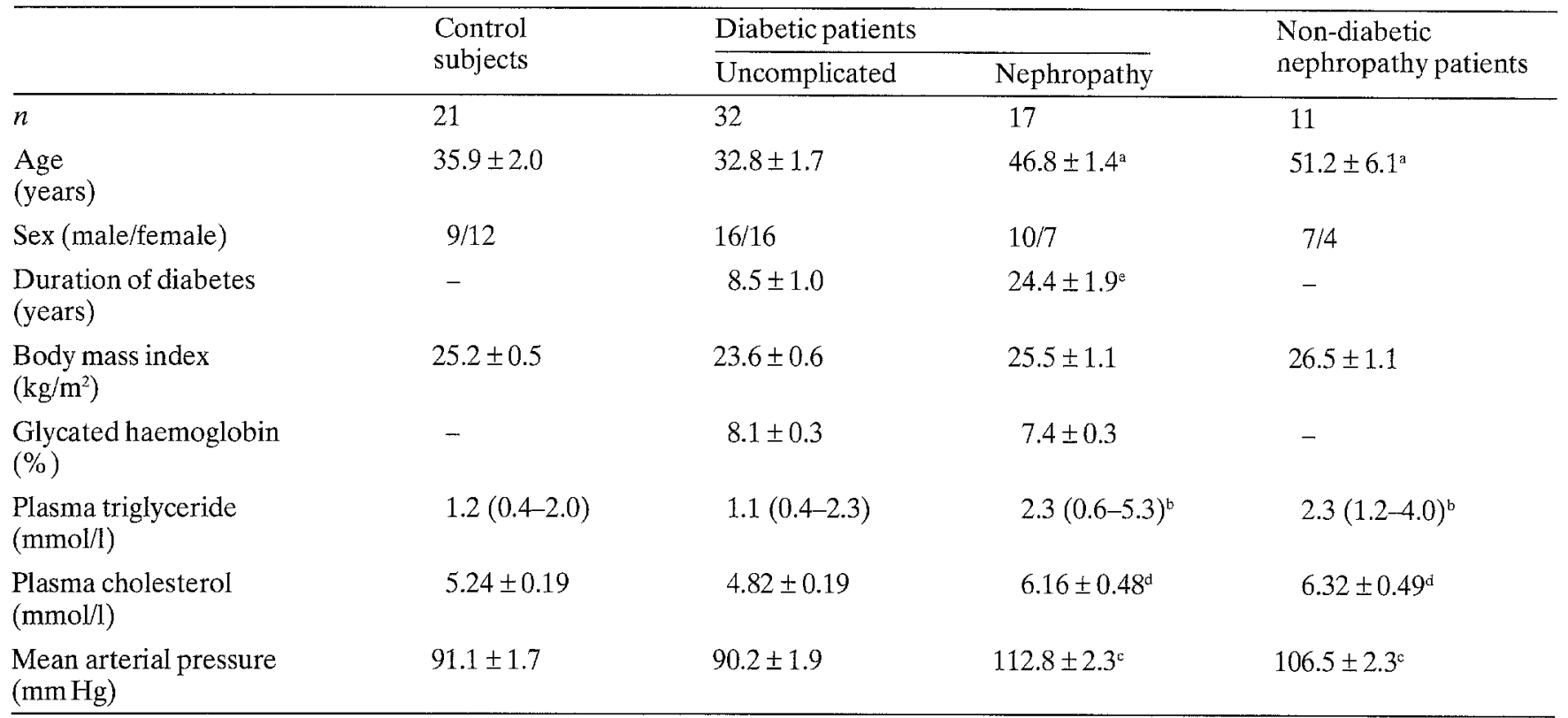

Values are mean \pm SEM.

${ }^{\mathrm{a}} p \leq 0.01,{ }^{\mathrm{b}} p<0.02,{ }^{\mathrm{c}} p<0.001$ vs control subjects and uncomplicated diabetic patients;

d $p<0.02,{ }^{\mathrm{e}} p<0.001$ vs uncomplicated diabetic patients

bated for up to $2 \mathrm{~h}$ (haematocrit of $10-16 \%$ ) at $37^{\circ} \mathrm{C}$ in choline medium and six sodium containing media with external sodium concentrations of $37.5,62.5,75.0,100.0,125.0$ and the standard $150.0 \mathrm{mmol} / \mathrm{l}$. SLC activity was determined by linear regression analysis as the difference between lithium efflux from erythrocytes in the sodium and choline media. The Eadie-Hofstee transformation of the Michaelis-Menten equation was used to calculate $\mathrm{k}_{\mathrm{m}}$ and $\mathrm{V}_{\max }$. The mean standard error of the slope of the lines from which $\mathrm{k}_{\mathrm{m}}$ and $\mathrm{V}_{\max }$ was determined was $5.6 \%$.

\section{Membrane preparation}

Erythrocyte ghosts were prepared using a method based on that of Dodge et al. [26]. Venous blood was collected in tubes containing lithium-heparin, centrifuged and the erythrocytes washed with isotonic phosphate buffered saline $(290 \pm 2 \mathrm{mosmol} / \mathrm{kg}$, $\mathrm{pH} 7.4)$ by repeated centrifugation $(3,000 \mathrm{rev} / \mathrm{min}, 4 \mathrm{~min})$. The erythrocytes were then lysed in hypotonic phosphate buffer ( $20 \pm 2 \mathrm{mosmol} / \mathrm{kg}, \mathrm{pH} 7.4$ ) containing $4 \mathrm{mmol} / 1 \mathrm{MgSO}_{4}$ to avoid alterations in membrane phospholipid alignment $[27,28]$. The ghosts were washed repeatedly with the hypotonic buffer to remove the haemoglobin. All steps in the preparation of the membranes were carried out at $4^{\circ} \mathrm{C}$. The protein concentration in the resulting membrane suspension was determined by the intensity of fluorescence emission of tryptophan [29] using bovine serum albumin as a standard and $2 \mathrm{mg}$ of membrane protein was then suspended in $3 \mathrm{ml}$ of isotonic phosphate buffer for fluorescence measurements.

\section{Fluidity measurements}

Membrane fluidity was assessed by the anisotropy of the fluorescent probes DPH and TMA-DPH $[30,31]$ (Sigma Chemical Company Ltd., Poole, Dorset, UK). Stock solutions of the probes were prepared in tetrahydrofuran and $\mathrm{N}, \mathrm{N}$-dimethyl- formamide respectively at a concentration of $2 \times 10^{-3} \mathrm{~mol} / \mathrm{l}$ and stored in the dark at $4^{\circ} \mathrm{C}$. For DPH, labelling was carried out on the erythrocyte membranes prior to hypotonic lysis by adding DPH stock solution to vigourously stirred isotonic phosphate buffer to make a suspension of concentration $2 \times 10^{-6} \mathrm{~mol} / \mathrm{l}$ DPH. An aliquot $(10 \mathrm{ml})$ of this DPH suspension was mixed with $0.5 \mathrm{ml}$ of erythrocytes and incubated in the dark at $37^{\circ} \mathrm{C}$ for 30 min. After labelling with DPH, the erythrocyte ghosts were prepared as described above. For TMA-DPH, labelling was carried out on the ghost membranes by adding $3 \mu$ of the stock solution of TMA-DPH to $3 \mathrm{ml}$ of the final membrane suspension and incubating in the dark for $5 \mathrm{~min}$ before making the fluorescence measurements.

Steady-state fluorescence polarization intensity was measured with a Perkin Elmer LS50 spectrometer equipped with integral polarizers (Perkin Elmer, Beaconsfield, Bucks., UK). Excitation and emission wavelengths were $359 \mathrm{~nm}$ and $440 \mathrm{~nm}$ respectively for DPH, and $361 \mathrm{~nm}$ and $454 \mathrm{~nm}$ for TMA-DPH. The measured anisotropies were obtained from the intensities of emission polarized parallel $\left(\mathrm{I}_{11}\right)$ and perpendicular $\left(\mathrm{I}_{1}\right)$ to the polarized excitation beam. Standard formulae were used including an appropriate grating correction $(\mathrm{G})$ :

Anisotropy $=\frac{I_{11}-I_{\underline{\underline{1}}} \cdot G}{I_{11}+2 \underline{I_{\underline{I}}} \cdot G}$

Light scattering errors were minimised by use of a $390 \mathrm{~nm}$ emission filter and by measuring the anisotropy at several dilutions and extrapolating to zero membrane concentration to obtain readings that were independent of concentration [32].

\section{Statistical analysis}

Results that had a normal distribution are given as mean \pm SEM, or where data were not normally distributed as median and range. The significance of differences between groups was assessed using the unpaired Student's $t$-test on normally dis- 
Table 2. Standard SLC activity, SLC kinetics and DPH and TMA-DPH anisotropy in control subjects, diabetic patients and nephropathy patients

\begin{tabular}{|c|c|c|c|c|}
\hline & \multirow{2}{*}{$\begin{array}{l}\text { Control } \\
\text { subjects }\end{array}$} & \multicolumn{2}{|l|}{ Diabetic patients } & \multirow{2}{*}{$\begin{array}{l}\text { Non-diabetic } \\
\text { nephropathy patients }\end{array}$} \\
\hline & & Uncomplicated & Nephropathy & \\
\hline$n$ & 21 & 32 & 17 & 11 \\
\hline $\begin{array}{l}\text { Maximum velocity }\left(V_{\max }\right) \\
(m \operatorname{mol} \mathrm{Li} / \mathrm{h} \times 1 \text { cells })\end{array}$ & $0.385 \pm 0.022$ & $0.528 \pm 0.035^{\mathrm{a}}$ & $0.414 \pm 0.056$ & $0.460 \pm 0.030$ \\
\hline DPH anisotropy & $0.214 \pm 0.0007$ & $0.210 \pm 0.0009^{\mathrm{d}}$ & $0.214 \pm 0.0014$ & $0.214 \pm 0.0010$ \\
\hline TMA-DPH anisotropy & $0.234 \pm 0.0012$ & $0.234 \pm 0.0009$ & $0.236 \pm 0.0020$ & $0.235 \pm 0.0007$ \\
\hline
\end{tabular}

Values are mean \pm SEM or median (range).

${ }^{\mathrm{a}} p \leq 0.001,{ }^{\mathrm{b}} p<0.05$ vs control subjects;

${ }^{\mathrm{c}} p<0.001$ vs control subjects, uncomplicated diabetic and non-

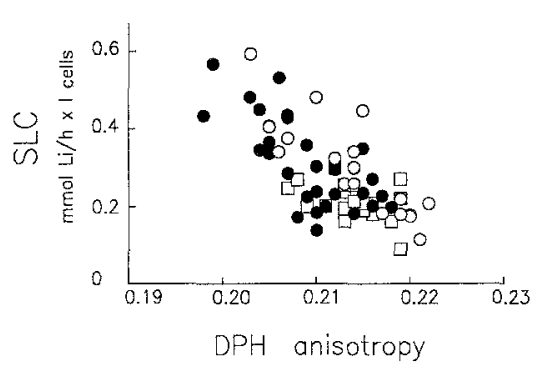

Fig. 1. Relationship between standard SLC activity and DPH anisotropy in normal control subjects $(\square)$ and diabetic patients: uncomplicated $(\bullet)$ and with nephropathy $(O)$

tributed values, or the Mann-Whitney U-test where data were not normally distributed. Calculation of correlation between variables was made using Spearman's rank correlation coefficients $\left(r_{\mathrm{s}}\right)$. The best fit line of $y$ on $x$ was determined by least squares regression analysis.

\section{Results}

No difference was observed in body mass index or glycaemic control between patients with uncomplicated diabetes and those with diabetic nephropathy. However, as may have been expected, diabetic patients with nephropathy were older, had a longer duration of diabetes and had raised serum lipids and mean arterial blood pressure compared to uncomplicated diabetic patients (Table 1). Non-diabetic patients with nephropathy also had raised levels of serum lipids and mean arterial pressure to a similar degree to patients with diabetic nephropathy.

The mean standard SLC activity (measured at $150 \mathrm{mmol} / 1$ external sodium concentration) was higher in both groups of diabetic patients compared to the control subjects (Table 2). However, there was a large region of overlap with $38 \%$ of uncomplicated and $41 \%$ diabetic nephropathy patients;

${ }^{\mathrm{d}} p<0.001$ vs control subjects, $p<0.02$ vs diabetic and nondiabetic nephropathy patients

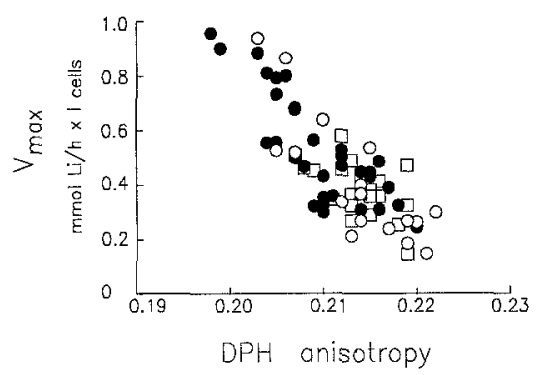

Fig.2. Relationship between $V_{\max }$ and DPH anisotropy in normal control subjects $(\square)$ and diabetic patients: uncomplicated (๑) and with nephropathy (O)

of diabetic nephropathy patients having values greater than the control range. In the uncomplicated patients, raised standard SLC was due to an increase in the $V_{\max }$ but in the patients with nephropathy, the raised SLC was due to a lower $k_{m}$. There was no evidence that the values for $k_{m}$ of SLC were affected by renal failure as the non-diabetic patients with nephropathy had values for $\mathrm{k}_{\mathrm{m}}$ that were not different to the control group. Standard SLC however, was raised in the patients with non-diabetic nephropathy compared with control subjects and was largely due to raised values for $V_{\max }$ which reached borderline statistical significance $(p=0.053)$.

The anisotropy value for the fluorescence of DPH in the erythrocyte membrane was lower in the uncomplicated diabetic patients than in the control subjects and in these patients was correlated with both standard SLC $\left(r_{\mathrm{s}}=-0.68, p=<0.001\right.$ : regression slope $=$ $-15.08 \pm 2.67$, intercept $=3.47 \pm 0.56$ : Fig. 1$)$ and $V_{\max }$ $\left(r_{\mathrm{s}}=-0.77, p=<0.001\right.$ : regression slope $=-30.54 \pm$ 3.80 , intercept $=6.93 \pm 0.80$ : Fig. 2 ). DPH anisotropy in patients with diabetic nephropathy was not different from the control group but was correlated with standard SLC $\left(r_{\mathrm{s}}=-0.72, p<0.001\right.$ : regression slope $=$ $-18.05 \pm 3.88$, intercept $=4.16 \pm 0.83)$ and $V_{\max }\left(r_{\mathrm{s}}=\right.$ 
$-0.73, p<0.001$ : regression slope $=-32.51 \pm 6.49$, intercept $=7.36 \pm 1.39$ ). DPH anisotropy and $V_{\max }$ were also correlated in the control subjects $\left(r_{\mathrm{s}}=-0.48, p=\right.$ 0.028: regression slope $=-15.89 \pm 6.22$, intercept $=$ $3.78 \pm 1.33)$ and the non-diabetic nephropathy group $\left(r_{\mathrm{s}}=-0.80, p=0.003:\right.$ regression slope $=-21.88 \pm$ 7.76 , intercept $=5.13 \pm 1.66$ ). There was no relationship however, between $\mathrm{k}_{\mathrm{m}}$ for SLC and DPH anisotropy in any of the groups studied $\left(r_{\mathrm{s}}=-0.06\right.$ to $+0.12, p>0.1$ in all four groups).

The anisotropy value for TMA-DPH was not different between the uncomplicated diabetic patients and those with nephropathy. There was also no difference between the diabetic patients and either normal control subjects or non-diabetic patients with nephropathy. The anisotropy value for TMA-DPH was not related to SLC or either of its kinetic parameters.

Standard SLC and $\mathrm{V}_{\max }$ were both correlated with serum triglycerides $\left(r_{\mathrm{s}}=0.35, p=0.002\right.$ and $r_{\mathrm{s}}=0.29$, $p=0.01$, respectively). This has been reported previously $[25,33]$. However, no correlations between membrane fluidity and serum lipids were seen. In addition, there were no significant relationships between glycated haemoglobin, age, sex, body mass index or mean arterial pressure and membrane fluidity or SLC.

\section{Discussion}

The group of patients with uncomplicated IDDM of relatively short duration had raised standard SLC. The kinetic mechanism for the high values was an increase in $\mathrm{V}_{\max }$ of the transporter. In addition, patients with diabetic nephropathy were found to have a low $\mathrm{k}_{\mathrm{m}}$. These findings are similar to those of previous studies $[4,16]$. However, $V_{\max }$ was not different in the diabetic nephropathy group compared to the control subjects which differs from a previous report [16] in which $V_{\text {max }}$ was lower in diabetic nephropathy patients. The reason for this may be that the high plasma triglyceride levels of the patients with nephropathy in the present study would have the effect of raising $V_{\max }[25,33]$ which would offset any reduction in $V_{\max }$ as a result of the presence of diabetic nephropathy alone.

The erythrocyte sodium-lithium countertransporter is a transmembrane protein and like other such proteins is probably closely associated with lipid molecules of the lipid bilayer. Its function may be regulated by interactions with bilayer lipids. In support of this, the present results show a strong relationship between membrane fluidity in the deep hydrophobic regions and SLC in uncomplicated IDDM. This relationship between SLC and fluidity would seem to be specific to the deep hydrophobic regions of the membrane however, as there was no correlation between TMA-DPH anisotropy and SLC. Therefore, the raised $V_{\max }$ of SLC in uncomplicated IDDM is associated with increased membrane fluidity in the deep hydrophobic regions of the erythrocyte membrane.

SLC was also related to DPH anisotropy in the diabetic nephropathy group. It is clear from the relationship between DPH anisotropy and the kinetic parameters $k_{m}$ and $V_{\max }$, that the relationship between membrane fluidity and $V_{\max }$ is the same in both uncomplicated diabetic patients and those with nephropathy. This strongly supports a primary relationship between $\mathrm{V}_{\max }$ and membrane fluidity. As the diabetic nephropathy patients have lower $\mathrm{k}_{\mathrm{m}} \mathrm{s}$, then they would be expected to have higher values of standard SLC for a given $\mathrm{V}_{\text {max }}$. Although standard SLC was raised in this group to a similar level as the uncomplicated diabetic patients, $V_{\max }$ was not raised, and neither was membrane fluidity as assessed by DPH anisotropy. Therefore, the relationship between standard SLC and DPH anisotropy is different from that in uncomplicated diabetic patients in that for a given value for DPH anisotropy, the SLC tends to be higher.

SLC was also raised in the non-diabetic nephropathy group. This may be due to the associated hyperlipidaemia as SLC is known to be raised during hyperlipidaemia, for which the kinetic mechanism is a raised $\mathrm{V}_{\max }[25,33]$. A similar degree of hyperlipidaemia in the diabetic nephropathy group would also tend to have the effect of raising $V_{\max }$. However, $V_{\max }$ was not raised in the group of patients with diabetic nephropathy. Therefore, raised plasma triglycerides cannot explain the difference in $V_{\max }$ between patients with uncomplicated diabetes and those with diabetic nephropathy.

The anisotropy value for DPH was lower in uncomplicated IDDM patients than normal control subjects. As anisotropy and fluidity are inversely related, this indicates increased fluidity in the deep hydrophobic regions of the erythrocyte membrane. This has been reported in previous studies [5-8], although others have also reported normal $[9,10]$ or lower fluidity $[11-13]$ as assessed by DPH in diabetes. The reason for these differences is not entirely clear. However, it should be noted that the patients studied in these reports often had different characteristics. The patients studied by Baba et al. [13] were mostly NIDDM patients. One group studied by Watala et al. [11] were juvenile IDDM patients of short duration and another [12] consisted of a mixed group of IDDM and NIDDM patients many of whom also had diabetic complications and had a longer duration of diabetes compared to the uncomplicated patients in the present study. The group studied by Birlouez-Argagon et al. [9] also contained some NIDDM patients but duration of diabetes and presence/absence of complications were not mentioned. The patients studied by Hill et al. [10] had a similar duration of diabetes but were younger (9-19 years) and some patients had microvascular disease. The patients studied by Testa et al. [5], Mazzanti et al. [6], Juhan-Vague et al. [7] and Rahmani-Jourdheuil et al. [8] however, all had IDDM 
of similar duration and age to those patients in the present study, but some of the patients in these previous studies had diabetic complications. The results in the present study demonstrate that the presence of diabetic complications could affect membrane fluidity as those patients with diabetic nephropathy had lower membrane fluidity compared to their uncomplicated counterparts although this was not different when compared to normal control subjects. It has also been previously suggested that diabetic patients with microangiopathy might have an elevation of membrane cholesterol and consequently, lowered membrane fluidity [11]. In addition, if raised SLC is a marker for those diabetic patients at risk of nephropathy (as has been suggested) then studying patients with a relatively long duration of diabetes would eliminate those with a raised SLC since if development of nephropathy were likely, it would already have occurred. In fact previously described patients with uncomplicated diabetes of relatively long duration do not have raised values for SLC $[16,24]$. Therefore since the present study shows a relationship between SLC and membrane fluidity, uncomplicated diabetic patients with a relatively long duration of diabetes are also unlikely to have high values of membrane fluidity. These differences in patient characteristics may therefore partly explain some, but certainly not all, of the discrepancies in results of erythrocyte membrane fluidity in diabetes.

Our results show a relationship between the fluidity in the deep hydrophobic membrane regions and the $\mathrm{V}_{\max }$ of SLC such that, higher membrane fluidity was associated with higher $V_{\text {max }}$. In broad terms an increase in $V_{\max }$ could be due to a greater number of SLC transporter units in the membrane or an increase in the turnover number (ions transported per second) of each transporter unit. These cannot be distinguished at present because the number of transporters cannot be determined. Membrane fluidity could increase $V_{\max }$ by either of these proposed mechanisms. Firstly it has been suggested that at any one time, the transporters are not all present at the surface of the membrane but a change in the fluidity of the membrane could allow more of them to travel to the surface and be available for ion transport [34]. The second hypothesis suggests that a change in membrane fluidity could affect any conformational change in the transporter necessary for ion transport and so affect the turnover number.

In summary, therefore, raised SLC activity in uncomplicated IDDM may be due to altered physical properties of the membrane lipid bilayer. Such membrane alterations may be important in the subsequent development of nephropathy.

Acknowledgements. We are grateful to the Northern Counties Kidney Research Fund for supporting this work.

\section{References}

1. Jensen JS, Mathiesen ER, Norgaard Ket al. (1990) Increased blood pressure and erythrocyte sodium/lithium countertransport activity are not inherited in diabetic nephropathy. Diabetologia 33: 619-624

2. Elving LD, Wetzels JFM, deNobel E, Berden JHM (1991) Erythrocyte sodium-lithium countertransport is not different in type 1 (insulin-dependent) diabetic patients with and without nephropathy. Diabetologia 34: 126-128

3. Carr SJ, Mbanya J-C, Thomas TH et al. (1990) Increased glomerular filtration rate in patients with insulin-dependent diabetes and elevated erythrocyte sodium-lithium countertransport. N Engl J Med 322: 500-505

4. Rutherford PA, Thomas TH, Carr SJ, Taylor R, Wilkinson R (1992) Kinetics of sodium-lithium countertransport activity in patients with uncomplicated type 1 diabetes. Clin Sci 82: 291-299

5. Testa I, Rabini RA, Fumelli P, Bertoli E, Mazzanti L (1988) Abnormal membrane fluidity and acetylcholinesterase activity in erythrocytes from insulin-dependent diabetic patients. J Clin Endocrinol Metab 67: 1129-1133

6. Mazzanti L, Rabini RA, Testa I, Bertoli E (1989) Modifications induced by diabetes on the physicochemical and functional properties of erythrocyte plasma membrane. Eur J Clin Invest 19: 84-89

7. Juhan-Vague I, Rahmani-Jourdheuil D, Mishal Z et al. (1986) Correction by insulin added in vitro of abnormal membrane fluidity of the erythrocytes from type 1 (insulindependent) diabetic patients. Diabetologia 29: 417-420

8. Rahmani-Jourdeuil D, Juhan-Vague I, Roul C et al. (1987) Correction by pentoxifylline of the abnormal fluorescence polarization of erythrocyte membranes from diabetic patients. Eur J Clin Pharmacol 31: 725-728

9. Bilouez-Aragon I, Scalbert-Menateau P, Morawiec M, Shafiezadeh M (1990) Evidence for a relationship between protein glycation and red blood cell membrane fluidity. Biochem Biophys Res Commun 170: 1107-1113

10. Hill MA, Court JM (1983) Erythrocyte membrane fluidity in type 1 diabetes mellitus. Pathology 15: 449-451

11. Watala C, Kordacka M, Loba A, Jozwiak Z, Nowak S (1987) Analysis of membrane fluidity alterations and lipid disorders in type 1 diabetic children and adolescents. Acta Diabetol Lat 24: 141-148

12. Watala C, Winocour PD (1992) The relationship of chemical modification of membrane proteins and plasma lipoproteins to reduced membrane fluidity of erythrocytes from diabetic subjects. Eur J Clin Chem Clin Biochem 30: 513-519

13. Baba Y, Kai M, Kamada T, Setoyama S, Otsuji S (1986) Higher levels of erythrocyte membrane microviscosity in diabetes. Diabetes 28: 1138-1139

14. Krolewski AS, Canessa M, Warram JH et al. (1988) Predisposition to hypertension and susceptibility to renal disease in insulin-dependent diabetes mellitus. N Engl J Med 318: 140-145

15. Mangili R, Bending JJ, Scott G, Lai K, Gupta A, Viberti G (1988) Increased sodium-lithium countertransport activity in red cells of patients with insulin-dependent diabetes and nephropathy. N Engl J Med 318: 146 150

16. Rutherford PA, Thomas TH, Carr S, Taylor R, Wilkinson R (1992) Changes in erythrocyte sodium-lithium countertransport kinetics in diabetic nephropathy. Clin Sci 82:301-307

17. Carruthers A, Melchior DL (1986) How bilayer lipids affect membrane protein activity. TIBS 2:331-335

18. Carruthers A, Melchior DL (1984) Human erythrocyte hexose transporter activity is governed by bilayer lipid com- 
position in reconstituted vesicles. Biochemistry 23: 69016911

19. Yeagle PL (1989) Lipid regulation of cell membrane structure and function. FASEB 3: 1833-1842

20. Shiga T, Maeda N (1981) Influence of membrane fluidity on erythrocyte functions. Biorheology 17:485-499

21. Le Grimellec C, Friedlander G, Yandouzi EHE, Zlatkine P, Giocondi M-C (1992) Membrane fluidity and transport properties in epithelia. Kidney Int 42: 825-836

22. Donner M, Muller S, Stoltz JFG (1990) Fluorescence depolarization method in the study of dynamic properties of blood cells. Biorheology 27:367-374

23. Schachter D, Cogan U, Abbott RE (1982) Asymmetry of lipid dynamics in human erythrocyte membranes studied with permeant fluorophores. Biochemistry 21: 2146-2150

24. Zerbini G, Magnali R, Garbetta F, Bogniti E (1991) Red cell $\mathrm{Na} / \mathrm{Li}$ countertransport and risk of nephropathy in type 1 diabetes. Diabetes 40: 498A (Abstract)

25. Rutherford PA, Thomas TH, Wilkinson R (1992) Plasma lipids affect maximum velocity not sodium affinity of human erythrocyte sodium-lithium countertransport: distinction from hypertension. Eur J Clin Invest 22: 719-724

26. Dodge JT, Mitchell C, Hanahan D (1963) The preparation and characteristics of haemoglobin free ghosts of human erythrocytes. Arch Biochem Biophys 100: 119-130

27. Tanaka K-I, Ohnishi S-I (1976) Heterogeneity in the fluidity of intact erythrocyte membrane and its homogenization upon haemolysis. Biochim Biophys Acta 426: 218-231
28. Conner J, Gillum K, Schroit AJ (1990) Maintainance of lipid asymmetry in red blood cells and ghosts: effect of divalent cations and serum albumin on the transbilayer distribution of phosphatidylserine. Biochim Biophys Acta 1025: 82-86

29. Teale FWJ (1960) The ultraviolet fluorescence of proteins in neutral solution. Biochem J 76: 381-388

30. Shinitzky M, Barenholz Y (1978) Fluidity parameters of lipid regions determined by fluorescence polarization. Biochim Biophys Acta 515: 367-394

31. Prendergast FG, Haugland RP, Callahan PJ (1981) 1-[4-(trimethylamino)phenyl]-6-phenylhexa-1,3,5-triene: synthesis, fluorescence properties, and use as a fluorescence probe of lipid bilayers. Biochemistry 20: 7333-7338

32. Dickens BF, Snow TR, Green V, Weglicki WB (1988) The effect of erythrocyte associated light scattering on membrane fluorescence polarization. Mol Cell Biochem 79: 91-94

33. Dowd A, Thomas TH, Wilkinson R (1993) Increased human erythrocyte sodium-lithium countertransport in hyperlipidaemic patients may indicate increased membrane fluidity. Eur J Clin Invest 23: 102-107

34. Shinitzky M, Borochov H, Wilbrandt W (1979) Lipid fluidity as a physiological regulator of membrane transport and enzyme activities. In: Lassen UV, Ussing HH, Wieth JO (eds) Membrane transport in erythrocytes. Munksgaard, Copenhagen, pp 91-103 